\title{
Additive and non-additive genetic architecture of two different-sized populations of Scabiosa canescens
}

\author{
PATRIK WALDMANN \\ Department of Systematic Botany, University of Lund, Östra Vallgatan 14-20, SE-22361, Lund, Sweden
}

\begin{abstract}
Future adaptation to changes in the environment depends on the existence of additive genetic variances within populations. Recently, considerable attention has also been given to the non-additive component, which plays an important role in inbreeding depression and bottleneck situations. In this study, I used data from a North Carolina II crossing experiment, analysed with restricted maximumlikelihood methods, to estimate the additive and dominance genetic (co)variances for eight quantitative characters in two different-sized populations of Scabiosa canescens, a rare and threatened plant in Sweden. There was no evidence for genetic erosion in the small Hällestad population $(\approx 25$ individuals) relative to the large Åhus population ( $\approx 5000$ individuals). In fact, slightly higher heritabilities were found in the Hällestad population. The additive genetic variance was statistically significant for all traits in both populations, but only a few additive covariances reached significance. The Hällestad population also had higher mean levels and more traits with significant dominance variance than the Ahus population. The variance attributable to maternal effects was too low to be considered significant. There was only a weak correspondence between heritabilities for each trait in the present study and previous estimates based on open-pollinated families of the same populations, but the mean heritability (over characters) was consistent between the studies.
\end{abstract}

\section{Introduction}

Many species occur in small isolated populations owing to the increasing fragmentation of their habitats. It is widely assumed that such populations have a greater risk of extinction than historically large populations, and that both ecological and genetic factors contribute to the low survivorship of numerically small populations (Lande, 1998). Recently, considerable attention has been given to the importance of genetic factors (Frankham, 1995), with particular emphasis on inbreeding depression, fixation of mildly deleterious mutations and loss of heritable variation necessary for adaptation (Lynch, 1996; Lande, 1998). Unfortunately, genetic studies of rare, threatened species usually only focus on the population structure of relatively few allozymes and other marker genes (Schemske et al., 1994), making it difficult to evaluate the effect of population fragmentation on those characters that ultimately determine viability and fecundity, i.e. life history, physiology and morphology. Such characters are usually influenced by a

Correspondence. Present address: University of Oulu, Department of Biology, PO. Box 3000, FIN-90014, University of Oulu, Finland. E-mail: Patrik.Waldmann@oulu.fi large number of genes, each having a relatively small effect on the phenotype. In this regard, it is important to consider both additive and non-additive sources of phenotypic variation (Falconer \& Mackay, 1996; Lynch \& Walsh, 1998).

For a neutral quantitative character with pure additive genetic variance, equilibrium theory predicts that the loss of variation because of genetic drift should be inversely proportional to the effective population size and consequently the same as for neutral markers (Falconer \& Mackay, 1996). However, recent theoretical predictions suggest that population bottlenecks can lead to an increase in the additive genetic variance when some of the phenotypic variation is caused by dominance (Wang et al., 1998) or epistasis (LópezFanjul et al., 1999). Data from experimental populations have confirmed that the mean level of additive variance increases after bottlenecks (e.g. Bryant et al., 1986; Wang et al., 1998; Cheverud et al., 1999; LópezFanjul et al., 1999; but see Whitlock \& Fowler, 1999) and that some of these changes can be attributed to dominance (Wang et al., 1998; López-Fanjul et al., 1999). Hence, the presence of non-additive genetic variance may influence the short-term response to bottlenecks. 
Natural selection is expected to reduce additive genetic variation for adaptive quantitative characters (Falconer \& Mackay, 1996), but the rate of loss depends on many factors, such as the number of loci and the mutation rate (Houle et al., 1996; Bürger \& Gimelfarb, 1999). Hence, the ratio of additive to non-additive genetic variance should be lower for fitness characters than for traits not directly connected with fitness (Roff, 1997; Merilä \& Sheldon, 1999). Recent surveys of the literature support the hypothesis that fitness traits have low levels of additive variance (Roff, 1997; but see Houle, 1992 for an alternative explanation) and that the non-additive component therefore accounts for a greater fraction of the total genetic variance in such characters than in other types of character, e.g. morphology (Crnokrak \& Roff, 1995). This difference is most pronounced in natural populations, presumably because many morphological characters have been subjected to strong artificial selection in domesticated species (Crnokrak \& Roff, 1995).

In a previous study of two Scabiosa species, Waldmann \& Andersson (1998) used open-pollinated progenies to estimate the heritability and the level of population divergence $\left(Q_{\mathrm{ST}}\right)$ for eight phenotypic characters and to compare these estimates with the corresponding measures for allozyme markers. Besides documenting high heritabilities for most characters, especially in $S$. canescens, this investigation revealed extensive population differentiation in $S$. columbaria, with estimates of $Q_{\mathrm{ST}}$ exceeding the allozymic $F_{\mathrm{ST}}$ for all traits, whereas estimates of $Q_{\mathrm{ST}}$ and $F_{\mathrm{ST}}$ for $S$. canescens were more similar. Assuming that most of the variation was additive, these observations indicate that spatially varying selection has played a greater role in $S$. columbaria than in $S$. canescens (Waldmann \& Andersson, 1998). Natural selection has also been invoked to explain some of the differences in the genetic (co)variance matrices between populations of $S$. columbaria (Waldmann \& Andersson, 2000).

In the present investigation, I performed a factorial crossing experiment (North Carolina design II, Lynch \& Walsh, 1998) to estimate additive and dominance (co)variances for eight phenotypic characters in two $S$. canescens populations (Waldmann \& Andersson, 1998, 1999). Given the more than 100-fold difference in the size of these populations (see below) and the potential for genetic drift to reduce heritable variation when the number of individuals is small, it was particularly interesting to compare the level of additive (co)variance in the two populations. Another goal was to estimate the differences in the dominance (co)variances, not only between the two populations, but also between different types of character, e.g. fitness components vs. characters related to morphology and phe- nology. Finally, I compared the results from the present study with the results from previous investigations of this species (Waldmann \& Andersson, 1998, 1999, 2000). The partitioning of the genetic variation into additive and non-additive components was carried out with bivariate restricted maximum-likelihood (REML) procedures to account for lack of balance (Lynch \& Walsh, 1998).

\section{Materials and methods}

\section{Plant material}

Scabiosa canescens Waldst. \& Kit. (Dipsacaceae) is a diploid, perennial plant with blue, bisexual, self-compatible, insect-pollinated flowers arranged in dense, terminal inflorescences (heads). Each flower has a corolla with five unequal lobes and a short tube, five stamens, and a unilocular, inferior ovary with a single style. Scabiosa canescens is restricted to open grasslands (steppe-heaths) in eastern Europe, extending northwards to south Sweden (Skåne), and classified as 'vulnerable' in the Swedish red list of threatened plant species (Aronsson, 1999). The plant material in the present investigation originated from two populations used in previous surveys of allozyme diversity and quantitative genetic variation (Waldmann \& Andersson, 1998, 1999, 2000). These populations represent one site near the village of Hällestad (current population size $\approx 25$ plants) and another near the city of Åhus (current population size $\approx 5000$ plants), in the easternmost part of Skåne (distance between populations $\approx 70 \mathrm{~km}$ ). Both localities represent steppe-like sites with sandy soil. Judging from allozyme data, genotypic frequencies of these and other Swedish populations of $S$. canescens are close to their Hardy-Weinberg expectations (Waldmann \& Andersson, 1998).

\section{Crossing experiment}

A factorial crossing experiment was performed to assess patterns and amounts of genetic (co)variation for each population. In the summer of 1995 , I assigned 18 plants per population as parents (10 males and eight females) and then mated each male to each of the females, resulting in a total of 160 full-sib families (two populations $\times 10$ males $\times$ eight females). Inbreeding was minimized by emasculating each recipient head before cross-pollination and by restricting matings to plants from different maternal families.

In July 1996, 20 seeds per family were sown in pots with sandy soil. After germination, about 10 randomly selected seedlings from each family were planted in separate 2-litre pots with a mixture of standard soil 
$(\approx 90 \%)$, sand $(10 \%)$ and lime $(1 \%)$. The resulting plants, 708 from the Hällestad population and 689 from the Åhus population, were placed in a random pattern (i.e. completely randomized design) in a greenhouse and raised under standardized growth conditions (fertilized once a week and watered as needed). In November 1996, I counted the rosette leaves and measured the length of the longest leaf $(\mathrm{mm})$ on each individual. The plants were overwintered in an unheated greenhouse to enhance flowering in 1997.

In April 1997, the plants were returned to the original greenhouse. In the summer, each plant was scored for five additional traits: the length of the longest stem leaf $(\mathrm{mm})$, flowering date (number of days from sowing), maximum plant height, the total number of heads produced, flower size and the number of flowers in the first flowering head. Maximum plant height, head number and flower size were measured as in Waldmann \& Andersson (1998). Head number and flower number per head should be positively correlated with fecundity under a wide range of conditions and were therefore considered as 'fitness components'. All traits were standardized to zero mean and unit variance to avoid scale effects and to facilitate comparison between traits.

\section{Univariate analyses}

Assuming that the parents from each locality are representative samples of the same random-mating population, the crossing experiment corresponds to a North Carolina II design (Lynch \& Walsh, 1998). The phenotypic data for each population were analysed with the following random-effects model:

$y_{i j k}=\mu+s_{i}+d_{j}+s d_{i j}+e_{i j k}$

where $y_{i j k}$ is the $k$ th phenotype of the mating of the $i$ th male (sire) with the $j$ th female (dam), $\mu$ is the mean phenotype of the population, $s_{i}$ and $d_{j}$ are the additive effects of male $i$ and female $j, s d_{i j}$ is the interaction of the paternal and maternal plants $i$ and $j$, and $e_{i j k}$ is the environmental effect and the remainder of the genetic deviations. All effects are assumed to be normally distributed, independent, have zero expectations and variance components $\sigma_{s}^{2}, \sigma_{d}^{2}, \sigma_{s d}^{2}$ and $\sigma_{e}^{2}$. The total phenotypic variance is the sum of these components (Lynch \& Walsh, 1998):

$\sigma_{y}^{2}=\sigma_{s}^{2}+\sigma_{d}^{2}+\sigma_{s d}^{2}+\sigma_{e}^{2}$.

Because of the unbalanced data structure, the variance components were estimated using the restricted maximum-likelihood (REML) method (Shaw, 1987; Searle et al., 1992; Lynch \& Walsh, 1998) using the AIREML algorithm of the REML directive in GENSTAT 5.4 (1997). As a first step, the maternal variance (defined as the composite maternal effect; Lynch \& Walsh, 1998) was estimated:

$V_{\mathrm{M}}=\sigma_{d}^{2} \quad \sigma_{s}^{2}$.

An added variance component due to maternity would indicate a nongenetic contribution from the female parent in addition to the genetic influence. To evaluate the statistical significance of $V_{\mathrm{M}}$, the VFUNCTION directive in GENSTAT 5.4 (1997) was used to construct approximate $95 \%$ confidence intervals (CI) with the delta technique (Hohls, 1996; Lynch \& Walsh, 1998). Since all $V_{\mathrm{M}}$ values failed to reach significance (see below), both the sire and dam components are assumed to comprise $1 / 4$ of the additive variance $\left(V_{\mathrm{A}}\right)$. To improve the statistical precision of $V_{\mathrm{A}}$, the estimates from the male and female arrays were therefore combined:

$V_{\mathrm{A}}=2\left(\sigma_{s}^{2}+\sigma_{d}^{2}\right)$.

Assuming no epistatic variance $\left(V_{\mathrm{I}}=0\right)$, the dominance variance $\left(V_{\mathrm{D}}\right)$ was estimated as:

$V_{\mathrm{D}}=4 \sigma_{s d}^{2}$

(Lynch \& Walsh, 1998). Both $V_{\mathrm{A}}$ and $V_{\mathrm{D}}$ are multiples of their causal variance components, making it possible to test their significance with a likelihood-ratio test (Shaw, 1987). The statistical significance of $V_{\mathrm{D}}$ was evaluated by removing $\sigma_{s d}^{2}$ from the full model (see above) and testing the difference in deviance against a $\chi^{2}(1)$ distribution. The $P$-value was multiplied by 0.5 to account for the fact that the asymptotic distribution of the likelihood-ratio test for a single variance component (constrained to be positive) should be a $50: 50$ mixture of the $\chi^{2}(0)$ and the $\chi^{2}(1)$ distributions (Morrell, 1998). To evaluate the significance of $V_{\mathrm{A}}, \sigma_{s}^{2}$ and $\sigma_{d}^{2}$ were removed from the full model, the difference in deviance tested against a $\chi^{2}(2)$ distribution, and the $P$-value multiplied by 0.5 . The interaction term $\left(\sigma_{s d}^{2}\right)$ was retained in the model when it reached significance. The fraction of genetic variance attributable to dominance (Crnokrak \& Roff, 1995) was also calculated:

$D_{\alpha}=V_{\mathrm{D}} /\left(V_{\mathrm{D}}+V_{\mathrm{A}}\right)$.

Finally, the effect of different numbers of parental genotypes in the analyses was examined. In this case, heritability was first used to estimate the level of additive 
variation from the sire and dam variances (as in the other analyses):

$h_{s+d}^{2}=2\left(\frac{\sigma_{s}^{2}+\sigma_{d}^{2}}{\sigma_{y}^{2}}\right)$

and then a similar set of analyses was performed using only the sire component:

$h_{s}^{2}=4\left(\frac{\sigma_{s}^{2}}{\sigma_{y}^{2}}\right)$

The second approach is often used to provide 'clean' measures of additive variation (no maternal effects), but may yield estimates with low statistical precision when the number of parents is small, as is the case in factorial crossing designs. Approximate $95 \%$ CI of each $h^{2}$ value was estimated using the delta technique (Hohls, 1996).

\section{Bivariate analyses}

Quantification of additive and non-additive genetic covariances is fraught with severe statistical problems, especially when the experimental design is unbalanced (Lynch \& Walsh, 1998). To obtain such data in the present investigation, a matrix formulation was used to express the statistical model above as a general mixed model:

$\mathbf{y}=\mathbf{X}_{\beta}+\mathbf{Z}_{1} \mathbf{s}+\mathbf{Z}_{2} \mathbf{d}+\mathbf{Z}_{3} \mathbf{s d}+\mathbf{e}$,

where $\mathbf{y}$ is a column vector of observations, $\mathbf{X}$ is an incidence matrix for fixed effects, $\beta$ is a vector of fixed effects, $\mathbf{Z}_{1,2,3}$ are incidence matrices corresponding to the random effect vectors $\mathbf{s}$ (sire), $\mathbf{d}$ (dam) and sd (sireby-dam interaction), respectively, and $\mathbf{e}$ is an error vector. In the present study, there are no fixed effects except for the common mean $\mu$, so $\mathbf{X}$ consists of a summing vector of ones $\left(\mathbf{1}_{\mathrm{N}}\right)$. When the aim is to estimate covariances, two traits (1 and 2) can be combined into a single vector (modified from Searle et al., 1992):

$$
\begin{aligned}
& \mathbf{y}=\left[\begin{array}{l}
\mathbf{y}_{1} \\
\mathbf{y}_{2}
\end{array}\right] \quad \mathbf{X}=\left[\begin{array}{cc}
\mathbf{1}_{\mathrm{N}} & \mathbf{0} \\
\mathbf{0} & \mathbf{1}_{\mathrm{N}}
\end{array}\right] \beta=\left[\begin{array}{l}
\mu_{1} \\
\mu_{2}
\end{array}\right] \\
& \mathbf{Z}_{s}=\left[\begin{array}{cc}
\mathbf{Z}_{1} & \mathbf{0} \\
\mathbf{0} & \mathbf{Z}_{1}
\end{array}\right] \quad \mathbf{s}=\left[\begin{array}{l}
\mathbf{s}_{1} \\
\mathbf{s}_{2}
\end{array}\right] \\
& \mathbf{Z}_{d}=\left[\begin{array}{cc}
\mathbf{Z}_{2} & \mathbf{0} \\
\mathbf{0} & \mathbf{Z}_{2}
\end{array}\right] \quad \mathbf{d}=\left[\begin{array}{l}
\mathbf{d}_{1} \\
\mathbf{d}_{2}
\end{array}\right] \\
& \mathbf{Z}_{s d}=\left[\begin{array}{cc}
\mathbf{Z}_{3} & \mathbf{0} \\
\mathbf{0} & \mathbf{Z}_{3}
\end{array}\right] \quad \mathbf{s d}=\left[\begin{array}{l}
\mathbf{s d}_{1} \\
\mathbf{s d}_{2}
\end{array}\right] \quad \mathbf{e}=\left[\begin{array}{l}
\mathbf{e}_{1} \\
\mathbf{e}_{2}
\end{array}\right]
\end{aligned}
$$

and the casual covariance components (s, d, sd and e) can be obtained from:

$$
\begin{aligned}
\operatorname{var}(\mathbf{s}) & =\left[\begin{array}{cc}
\sigma_{s_{1}}^{2} \mathbf{I}_{a} & \tau_{s} \mathbf{I}_{a} \\
\tau_{s} \mathbf{I}_{a} & \sigma_{s_{2}}^{2} \mathbf{I}_{a}
\end{array}\right]=\left[\begin{array}{cc}
\sigma_{s_{1}}^{2} & \tau_{s} \\
\tau_{s} & \sigma_{s_{2}}^{2}
\end{array}\right] \otimes \mathbf{I}_{a} \\
\operatorname{var}(\mathbf{d}) & =\left[\begin{array}{ll}
\sigma_{d_{1}}^{2} \mathbf{I}_{b} & \tau_{d} \mathbf{I}_{b} \\
\tau_{d} \mathbf{I}_{b} & \sigma_{d_{2}}^{2} \mathbf{I}_{b}
\end{array}\right]=\left[\begin{array}{cc}
\sigma_{d_{1}}^{2} & \tau_{d} \\
\tau_{d} & \sigma_{d_{2}}^{2}
\end{array}\right] \otimes \mathbf{I}_{b} \\
\operatorname{var}(\mathbf{s d}) & =\left[\begin{array}{ll}
\sigma_{s d_{1}}^{2} \mathbf{I}_{c} & \tau_{s d} \mathbf{I}_{c} \\
\tau_{s d} \mathbf{I}_{c} & \sigma_{s d_{2}}^{2} \mathbf{I}_{c}
\end{array}\right]=\left[\begin{array}{cc}
\sigma_{s d_{1}}^{2} & \tau_{s d} \\
\tau_{s d} & \sigma_{s d_{2}}^{2}
\end{array}\right] \otimes \mathbf{I}_{c} \\
\operatorname{var}(\mathbf{e}) & =\left[\begin{array}{ll}
\sigma_{e_{1}}^{2} \mathbf{I}_{n} & \tau_{e} \mathbf{I}_{n} \\
\tau_{e} \mathbf{I}_{n} & \sigma_{e_{2}}^{2} \mathbf{I}_{n}
\end{array}\right]=\left[\begin{array}{cc}
\sigma_{e_{1}}^{2} & \tau_{e} \\
\tau_{e} & \sigma_{e_{2}}^{2}
\end{array}\right] \otimes \mathbf{I}_{n}
\end{aligned}
$$

where $\otimes$ denotes the Kronecker product, $a$ is the number of sires, $b$ the number of dams, $c$ the number of families, $n$ the total number of individuals, and $\mathbf{I}_{a, b, c}$ or $n$ the corresponding dispersion matrices. Following the combination of pairs of traits into single vectors, the causal covariance components were estimated with GENSTAT 5.4 (1997) using the VSTRUCTURE directive in combination with the AIREML algorithm (which allows for negative variances) of the REML directive. The additive genetic covariances between two characters was estimated as:

$C O V_{\mathrm{A}}=2\left(\tau_{s}+\tau_{d}\right)$

and the dominance covariance as:

$C O V_{\mathrm{D}}=4 \tau_{s d}$

The significance of the covariance components was evaluated with likelihood-ratio procedures as in the univariate analyses, except that the multiplication factor was omitted. Since all data were standardized before analysis, the estimates can be considered as scale-free measures of covariation. Hence, no attempt was made to calculate genetic correlations from the covariance components.

\section{Results}

\section{Additive (co)variances}

Analyses of residuals from the univariate REML analyses confirmed the normality assumption for all characters. The maternal effects were too small to be considered significant (the CI of $V_{\mathrm{M}}$ overlapped 0 in all cases, Table 1) and the two types of heritability estimates, $h^{2}{ }_{s+d}$ and $h_{s}^{2}$, had overlapping CI for all traits, despite sizable differences in some cases, e.g. rosette leaf length (Table 2). Hence, estimates of the 


\begin{tabular}{|c|c|c|c|c|}
\hline \multirow[b]{2}{*}{ Trait } & \multicolumn{2}{|c|}{ Hällestad } & \multicolumn{2}{|c|}{ Åhus } \\
\hline & $V_{\mathrm{M}}$ & CI & $V_{\mathrm{M}}$ & $\mathrm{CI}$ \\
\hline Rosette leaf no. & -0.242 & $-0.522,0.038$ & -0.013 & $-0.179,0.152$ \\
\hline Rosette leaf length & 0.098 & $-0.083,0.278$ & 0.143 & $-0.068,0.354$ \\
\hline Stem leaf length & -0.062 & $-0.277,0.153$ & -0.070 & $-0.248,0.108$ \\
\hline Plant height & -0.138 & $-0.321,0.046$ & 0.177 & $-0.155,0.509$ \\
\hline Head number & -0.147 & $-0.314,0.020$ & 0.036 & $-0.030,0.103$ \\
\hline Flowers per head & 0.013 & $-0.139,0.164$ & 0.037 & $-0.143,0.218$ \\
\hline Flowering date & -0.005 & $-0.316,0.307$ & 0.101 & $-0.156,0.357$ \\
\hline Flower size & -0.130 & $-0.326,0.065$ & 0.060 & $-0.121,0.242$ \\
\hline
\end{tabular}

Table 1 Estimates of the maternal variance $\left(V_{\mathrm{M}}\right)$ and their corresponding $95 \%$ confidence intervals $(\mathrm{CI})$ for the small Hällestad and the large Åhus populations of Scabiosa canescens. All estimates are based on data standardized to zero mean and unit variance

Table 2 Estimates of the heritability (above) and their 95\% confidence intervals (below) for the small Hällestad and the large Åhus populations of Scabiosa canescens $\left(h_{\mathrm{FS}}^{2}\right.$ are full-sib estimates from Waldmann \& Andersson (1998), whereas $h_{s}^{2}$ and $h^{2}{ }_{s+d}$ represent the narrow-sense estimates from the present study)

\begin{tabular}{|c|c|c|c|c|c|c|}
\hline \multirow[b]{2}{*}{ Trait } & \multicolumn{3}{|c|}{ Hällestad } & \multicolumn{3}{|c|}{ Åhus } \\
\hline & $h_{\mathrm{FS}}^{2}$ & $h_{s}^{2}$ & $h_{s+d}^{2}$ & $h_{\mathrm{FS}}^{2}$ & $h_{s}^{2}$ & $h_{s+d}^{2}$ \\
\hline \multirow{2}{*}{ Rosette leaf no. } & 0.009 & 1.077 & 0.616 & 1.010 & 0.425 & 0.399 \\
\hline & $-0.246 ; 0.264$ & $0.307 ; 1.847$ & $0.244 ; 0.988$ & $0.596 ; 1.418$ & $0.004 ; 0.846$ & $0.133 ; 0.665$ \\
\hline \multirow[t]{2}{*}{ Rosette leaf length } & 0.548 & 0.167 & 0.358 & 0.570 & 0.177 & 0.463 \\
\hline & $0.125 ; 0.970$ & $-0.078 ; 0.412$ & $0.062 ; 0.654$ & $0.149 ; 0.991$ & $-0.018 ; 0.371$ & $0.136 ; 0.791$ \\
\hline \multirow[t]{2}{*}{ Stem leaf length } & - & 0.655 & 0.535 & - & 0.570 & 0.432 \\
\hline & & $0.086 ; 1.224$ & $0.226 ; 0.844$ & & $0.052 ; 1.088$ & $0.151 ; 0.713$ \\
\hline \multirow[t]{2}{*}{ Plant height } & 0.691 & 0.660 & 0.391 & 0.270 & 0.416 & 0.768 \\
\hline & $0.251 ; 1.131$ & $0.079 ; 1.242$ & $0.097 ; 0.684$ & $-0.083 ; 0.623$ & $-0.013 ; 0.845$ & $0.356 ; 1.180$ \\
\hline \multirow{2}{*}{ Head number } & 0.414 & 0.625 & 0.340 & 0.739 & 0.017 & 0.089 \\
\hline & $0.007 ; 0.822$ & $0.081 ; 1.170$ & $0.067 ; 0.613$ & $0.307 ; 1.170$ & $-0.087 ; 0.120$ & $-0.042 ; 0.220$ \\
\hline \multirow[t]{2}{*}{ Flowers per head } & - & 0.318 & 0.343 & - & 0.371 & 0.443 \\
\hline & & $-0.027 ; 0.663$ & $0.096 ; 0.589$ & & $0.013 ; 0.729$ & $0.167 ; 0.718$ \\
\hline \multirow[t]{2}{*}{ Flowering date } & 0.557 & 0.748 & 0.740 & 0.098 & 0.416 & 0.612 \\
\hline & $0.125 ; 0.990$ & $0.106 ; 1.391$ & $0.378 ; 1.101$ & $-0.187 ; 0.383$ & $0.014 ; 0.818$ & $0.262 ; 0.962$ \\
\hline \multirow[t]{2}{*}{ Flower size } & 0.470 & 0.690 & 0.440 & 0.176 & 0.300 & 0.417 \\
\hline & $0.049 ; 0.891$ & $0.101 ; 1.278$ & $0.143 ; 0.737$ & $-0.143 ; 0.496$ & $-0.018 ; 0.619$ & $0.134 ; 0.700$ \\
\hline Mean & 0.448 & 0.618 & 0.470 & 0.477 & 0.336 & 0.452 \\
\hline
\end{tabular}

additive genetic variance from the average of the maternal and paternal half-sib variances were considered to be more accurate than those based solely on the sire component.

There was a close correspondence between $h^{2}+d$ (Table 2) and $V_{\mathrm{A}}$ (Tables 3 and 4 ), an expected result for standardized variables. The $h^{2}{ }_{s+d}$ estimates for the Hällestad population ranged from 0.340 to 0.740 and reached significance in all cases (CI excluded 0 , Table 2). Estimates for the Åhus population varied between 0.089 and 0.768 . Only the lowest value (head number) failed to reach significance. The heritability was more variable between traits than between populations: the average $h_{s+d}^{2}$ over all traits was 0.470 for the Hällestad population and 0.452 for the Åhus population. High values were found for flowering date (both populations), rosette leaf number (Hällestad) and plant height (Åhus), whereas the 'fitness components' (head number, flower number per head) had relatively low values (except for flower number per head in the Åhus population).

According to the bivariate analyses, the additive covariances $\left(C O V_{\mathrm{A}}\right)$ varied between -0.432 and 0.604 (12 negative and 16 positive) for the Hällestad population (Table 3 ) and between -0.474 and 0.323 (nine negative and 19 positive) for the Ahus population (Table 4). Statistically significant associations in the Hällestad population distinguished early flowering plants with long stem leaves and large flowers from those with the opposite features. A negative additive covariance between flowering date and flower size was also detected in the Åhus population. 
Table 3 Additive genetic (co)variance matrices for the small Hällestad population of Scabiosa canescens. The values below the diagonal are from the present study, whereas those above are from Waldmann \& Andersson, 2000. $P$-values of the (co)variance components are based on likelihood-ratio tests

\begin{tabular}{|c|c|c|c|c|c|c|c|c|}
\hline Trait & $\begin{array}{l}\text { Rosette } \\
\text { leaf no. }\end{array}$ & $\begin{array}{l}\text { Rosette } \\
\text { leaf length }\end{array}$ & $\begin{array}{l}\text { Stem leaf } \\
\text { length }\end{array}$ & $\begin{array}{l}\text { Plant } \\
\text { height }\end{array}$ & $\begin{array}{l}\text { Head } \\
\text { number }\end{array}$ & $\begin{array}{l}\text { Flowers } \\
\text { per head }\end{array}$ & $\begin{array}{l}\text { Flowering } \\
\text { size }\end{array}$ & $\begin{array}{c}\text { Flower } \\
\text { date }\end{array}$ \\
\hline $\begin{array}{l}\text { Rosette } \\
\text { leaf no. }\end{array}$ & $\begin{array}{l}-0.054 \\
0.647 \\
P<0.001\end{array}$ & 0.052 & - & 0.068 & 0.087 & - & -0.004 & 0.067 \\
\hline $\begin{array}{l}\text { Rosette leaf } \\
\text { length }\end{array}$ & $\begin{array}{l}0.054 \\
P=0.819\end{array}$ & $\begin{array}{l}0.485 \\
0.366 \\
P<0.001\end{array}$ & - & 0.298 & -0.047 & - & -0.192 & 0.287 \\
\hline $\begin{array}{l}\text { Stem leaf } \\
\text { length }\end{array}$ & $\begin{array}{l}-0.050 \\
P=0.956\end{array}$ & $\begin{array}{l}0.120 \\
P=0.647\end{array}$ & $\begin{array}{l}- \\
0.554 \\
P<0.001\end{array}$ & - & - & - & - & - \\
\hline Plant height & $\begin{array}{l}0.185 \\
P=0.123\end{array}$ & $\begin{array}{l}0.147 \\
P=0.025\end{array}$ & $\begin{array}{l}0.141 \\
P=0.512\end{array}$ & $\begin{array}{l}0.632 \\
0.400 \\
P<0.001\end{array}$ & 0.320 & - & -0.031 & -0.006 \\
\hline Head number & $\begin{array}{l}0.302 \\
P=0.087\end{array}$ & $\begin{array}{l}0.040 \\
P=0.268\end{array}$ & $\begin{array}{l}-0.179 \\
P=0.281\end{array}$ & $\begin{array}{l}0.164 \\
P=0.331\end{array}$ & $\begin{array}{l}0.344 \\
0.350 \\
P<0.001\end{array}$ & - & 0.086 & -0.126 \\
\hline $\begin{array}{l}\text { Flowers } \\
\text { per head }\end{array}$ & $\begin{array}{l}-0.056 \\
P=0.207\end{array}$ & $\begin{array}{l}0.023 \\
P=0.844\end{array}$ & $\begin{array}{l}-0.131 \\
P=0.166\end{array}$ & $\begin{array}{l}0.039 \\
P=0.918\end{array}$ & $\begin{array}{l}-0.111 \\
P=0.199\end{array}$ & $\begin{array}{l}- \\
0.356 \\
P<0.001\end{array}$ & - & - \\
\hline $\begin{array}{l}\text { Flowering } \\
\text { date }\end{array}$ & $\begin{array}{l}0.039 \\
P=0.748\end{array}$ & $\begin{array}{l}-0.013 \\
P=0.975\end{array}$ & $\begin{array}{l}0.604 \\
P<0.001\end{array}$ & $\begin{array}{l}0.038 \\
P=0.827\end{array}$ & $\begin{array}{l}-0.069 \\
P=0.896\end{array}$ & $\begin{array}{l}-0.194 \\
P=0.328\end{array}$ & $\begin{array}{l}0.502 \\
0.818 \\
P<0.001\end{array}$ & -0.367 \\
\hline Flower size & $\begin{array}{l}-0.092 \\
P=0.654\end{array}$ & $\begin{array}{l}0.100 \\
P=0.604\end{array}$ & $\begin{array}{l}-0.320 \\
P=0.022\end{array}$ & $\begin{array}{l}-0.001 \\
P=0.130\end{array}$ & $\begin{array}{l}0.029 \\
P=0.909\end{array}$ & $\begin{array}{l}0.128 \\
P=0.557\end{array}$ & $\begin{array}{l}-0.432 \\
P<0.001\end{array}$ & $\begin{array}{l}0.445 \\
0.458 \\
P<0.001\end{array}$ \\
\hline
\end{tabular}

Adjusting the significance level for multiple comparisons $(P=0.0062$ for variances and $P=0.0018$ for covariances) did not alter the general conclusions of the additive (co)variances.

\section{Dominance (co)variances}

Data from the Hällestad population indicate significant levels of dominance variance $\left(V_{\mathrm{D}}\right)$ for all characters, with estimates ranging from 0.120 to 0.485 (five remained significant at the $P=0.0062$ level; Table 5). Estimates of $V_{\mathrm{D}}$ for the Åhus population were lower, ranging between 0 and 0.294 , and only four values were significantly different from 0 (three were significant at the $P=0.0062$ level; Table 5). Hence, the mean level of variance attributed to dominance was higher for the Hällestad population (0.263) than for the Âhus population (0.149). No tendency was found for 'fitness components' to have a higher level of dominance variance than other characters. The contribution of dominance variance to the total genetic variance $\left(D_{\alpha}\right)$ in the Hällestad population was found to be 0.411 for flower number per head and 0.312 for head number, whereas the other traits had intermediate values (mean $D_{\alpha}=0.342$ ). As for the Ahus population, $D_{\alpha}$ was higher for head number (0.738) than for flower number per head (0) and the remaining characters (mean $D_{\alpha}=0.217$ ).

Regarding the covariances $\left(C O V_{\mathrm{D}}\right)$, the Hällestad population showed a wider range of values $(-0.209$ to $0.293 ; 22$ positive and six negative) than the Ahus population $(-0.055$ to $0.256 ; 18$ positive and 10 negative). The majority of the estimates were significantly different from 0 in the Hällestad population (18 out of 
Table 4 Additive genetic (co)variance matrices for the large Åhus population of Scabiosa canescens. The values below the diagonal are from the present study, whereas those above are from Waldmann \& Andersson, 2000, $P$-values of the (co)variance components are based on likelihood-ratio tests

\begin{tabular}{|c|c|c|c|c|c|c|c|c|}
\hline Trait & $\begin{array}{l}\text { Rosette } \\
\text { leaf no. }\end{array}$ & $\begin{array}{l}\text { Rosette } \\
\text { leaf length }\end{array}$ & $\begin{array}{l}\text { Stem leaf } \\
\text { length }\end{array}$ & $\begin{array}{l}\text { Plant } \\
\text { height }\end{array}$ & $\begin{array}{l}\text { Head } \\
\text { number }\end{array}$ & $\begin{array}{l}\text { Flowers } \\
\text { per head }\end{array}$ & $\begin{array}{c}\text { Flowering } \\
\text { size }\end{array}$ & $\begin{array}{c}\text { Flower } \\
\text { date }\end{array}$ \\
\hline $\begin{array}{l}\text { Rosette } \\
\text { leaf no. }\end{array}$ & $\begin{array}{l}0.688 \\
0.404 \\
P<0.001\end{array}$ & 0.024 & - & -0.227 & 0.160 & - & -0.150 & -0.111 \\
\hline $\begin{array}{l}\text { Rosette } \\
\text { leaf length }\end{array}$ & $\begin{array}{l}0.124 \\
P=0.527\end{array}$ & $\begin{array}{l}0.234 \\
0.462 \\
P<0.001\end{array}$ & - & -0.028 & 0.055 & - & 0.021 & -0.039 \\
\hline $\begin{array}{l}\text { Stem leaf } \\
\text { length }\end{array}$ & $\begin{array}{l}-0.008 \\
P=0.990\end{array}$ & $\begin{array}{l}0.092 \\
P=0.119\end{array}$ & $\begin{array}{l}- \\
0.437 \\
P<0.001\end{array}$ & - & - & - & - & - \\
\hline Plant height & $\begin{array}{l}0.147 \\
P=0.644\end{array}$ & $\begin{array}{l}0.147 \\
P=0.366\end{array}$ & $\begin{array}{l}0.323 \\
P=0.056\end{array}$ & $\begin{array}{l}0.270 \\
0.773 \\
P<0.001\end{array}$ & 0.225 & - & 0.166 & 0.120 \\
\hline Head number & $\begin{array}{l}0.098 \\
P=0.193\end{array}$ & $\begin{array}{l}0.002 \\
P=0.744\end{array}$ & $\begin{array}{l}0.028 \\
P=0.844\end{array}$ & $\begin{array}{l}0.103 \\
P=0.445\end{array}$ & $\begin{array}{l}0.638 \\
0.089 \\
P=0.0248\end{array}$ & - & 0.105 & -0.004 \\
\hline $\begin{array}{l}\text { Flowers } \\
\text { per head }\end{array}$ & $\begin{array}{l}0.131 \\
P=0.512\end{array}$ & $\begin{array}{l}0.233 \\
P=0.113\end{array}$ & $\begin{array}{l}0.039 \\
P=0.878\end{array}$ & $\begin{array}{l}0.227 \\
P=0.294\end{array}$ & $\begin{array}{l}-0.089 \\
P=0.231\end{array}$ & $\begin{array}{l}- \\
0.458 \\
P<0.001\end{array}$ & - & - \\
\hline $\begin{array}{l}\text { Flowering } \\
\text { date }\end{array}$ & $\begin{array}{l}-0.022 \\
P=0.549\end{array}$ & $\begin{array}{l}-0.006 \\
P=0.489\end{array}$ & $\begin{array}{l}0.113 \\
P=0.622\end{array}$ & $\begin{array}{l}-0.167 \\
P=0.372\end{array}$ & $\begin{array}{l}-0.140 \\
P=0.222\end{array}$ & $\begin{array}{l}0.124 \\
P=0.104\end{array}$ & $\begin{array}{l}0.066 \\
0.629 \\
P<0.001\end{array}$ & -0.020 \\
\hline Flower size & $\begin{array}{l}-0.025 \\
P=0.705\end{array}$ & $\begin{array}{l}-0.024 \\
P=0.715\end{array}$ & $\begin{array}{l}0.050 \\
P=0.905\end{array}$ & $\begin{array}{l}0.279 \\
P=0.121\end{array}$ & $\begin{array}{l}0.113 \\
P=0.313\end{array}$ & $\begin{array}{l}0.001 \\
P=0.525\end{array}$ & $\begin{array}{l}-0.474 \\
P<0.001\end{array}$ & $\begin{array}{l}0.119 \\
0.430 \\
P<0.001\end{array}$ \\
\hline
\end{tabular}

28 at the $P=0.05$ level), contrasting with the small number of significant values in the Ahus population (three out of 28 at the $P=0.05$ level). However, when adjusted for multiple comparisons $(P=0.0018)$, the difference in significant estimates was smaller (three for Hällestad and one for Åhus; Table 5). The average strength of association attributed to dominance effects was higher for plants from the Hällestad population (0.163) than for plants from the Åhus population (0.051). All significant estimates were positive, except for three negative associations involving flowering date (Hällestad) (Table 5).

\section{Discussion}

Since genetic drift is a stochastic process, one would expect wide fluctuations in quantitative genetic param- eters from one generation (or population) to another, even for populations with effective sizes of a few hundreds (Zeng \& Cockerham, 1991; Bürger \& Lande, 1994). Estimates of (co)variance components are also likely to differ between different samples from the same population, particularly when samples are small (Lynch, 1996). The latter problem is most severe in factorial experiments involving a relatively small number of parents from the source population(s). Sample sizes in the present investigation were relatively small (18 parents and about 700 offspring per population), and therefore the effect of sampling variability was substantial, as demonstrated by the wide confidence intervals of most heritability estimates. Furthermore, there was only a weak correspondence between heritabilities in the present study and those reported by Waldmann \& Andersson (1998), especially for plants derived from the 
Table 5 Dominance (co)variance matrices for the small Hällestad population (lower left) and the large Åhus population (upper right) of Scabiosa canescens. $P$-values of the (co)variance components are based on likelihood-ratio tests

\begin{tabular}{|c|c|c|c|c|c|c|c|c|}
\hline Trait & $\begin{array}{l}\text { Rosette } \\
\text { leaf no. }\end{array}$ & $\begin{array}{l}\text { Rosette } \\
\text { leaf length }\end{array}$ & $\begin{array}{l}\text { Stem leaf } \\
\text { length }\end{array}$ & $\begin{array}{l}\text { Plant } \\
\text { height }\end{array}$ & $\begin{array}{l}\text { Head } \\
\text { number }\end{array}$ & $\begin{array}{l}\text { Flowers } \\
\text { per head }\end{array}$ & $\begin{array}{c}\text { Flowering } \\
\text { size }\end{array}$ & $\begin{array}{c}\text { Flower } \\
\text { date }\end{array}$ \\
\hline $\begin{array}{l}\text { Rosette } \\
\text { leaf no. }\end{array}$ & $\begin{array}{l}0.220 \\
P=0.002 \\
0.120 \\
P=0.033\end{array}$ & $\begin{array}{l}0.001 \\
P=1.000\end{array}$ & $\begin{array}{l}0.011 \\
P=0.888\end{array}$ & $\begin{array}{l}-0.055 \\
P=0.458\end{array}$ & $\begin{array}{l}0.110 \\
P=0.169\end{array}$ & $\begin{array}{l}-0.018 \\
P=0.752\end{array}$ & $\begin{array}{l}0.007 \\
P=0.888\end{array}$ & $\begin{array}{l}0.025 \\
P=0.729\end{array}$ \\
\hline $\begin{array}{l}\text { Rosette } \\
\text { leaf length }\end{array}$ & $\begin{array}{l}0.108 \\
P=0.163\end{array}$ & $\begin{array}{l}0 \\
P=0.187 \\
0.485 \\
P<0.001\end{array}$ & $\begin{array}{l}0.038 \\
P=0.475\end{array}$ & $\begin{array}{l}-0.008 \\
P=0.862\end{array}$ & $\begin{array}{l}-0.008 \\
P=0.920\end{array}$ & $\begin{array}{l}0.034 \\
P=0.458\end{array}$ & $\begin{array}{l}0.051 \\
P=0.306\end{array}$ & $\begin{array}{l}-0.003 \\
P=0.920\end{array}$ \\
\hline $\begin{array}{l}\text { Stem leaf } \\
\text { length }\end{array}$ & $\begin{array}{l}0.052 \\
P=0.424\end{array}$ & $\begin{array}{l}0.187 \\
P=0.030\end{array}$ & $\begin{array}{l}0.221 \\
P=0.001 \\
0.222 \\
P=0.003\end{array}$ & $\begin{array}{l}0.256 \\
P<0.001\end{array}$ & $\begin{array}{l}0.176 \\
P=0.024\end{array}$ & $\begin{array}{l}0.149 \\
P=0.008\end{array}$ & $\begin{array}{l}-0.005 \\
P=0.920\end{array}$ & $\begin{array}{l}0.003 \\
P=0.920\end{array}$ \\
\hline Plant height & $\begin{array}{l}0.073 \\
P=0.296\end{array}$ & $\begin{array}{l}0.215 \\
P=0.021\end{array}$ & $\begin{array}{l}0.206 \\
P=0.007\end{array}$ & $\begin{array}{l}0.294 \\
P<0.001 \\
0.326 \\
P<0.001\end{array}$ & $\begin{array}{l}0.155 \\
P=0.050\end{array}$ & $\begin{array}{l}0.052 \\
P=0.406\end{array}$ & $\begin{array}{l}-0.019 \\
P=0.764\end{array}$ & $\begin{array}{l}0.035 \\
P=0.610\end{array}$ \\
\hline $\begin{array}{l}\text { Head } \\
\text { number }\end{array}$ & $\begin{array}{l}0.047 \\
P=0.446\end{array}$ & $\begin{array}{l}0.186 \\
P=0.026\end{array}$ & $\begin{array}{l}0.145 \\
P=0.034\end{array}$ & $\begin{array}{l}0.230 \\
P=0.001\end{array}$ & $\begin{array}{l}0.251 \\
P=0.004 \\
0.159 \\
P=0.020\end{array}$ & $\begin{array}{l}0.088 \\
P=0.199\end{array}$ & $\begin{array}{l}-0.015 \\
P=0.823\end{array}$ & $\begin{array}{l}0.032 \\
P=0.671\end{array}$ \\
\hline $\begin{array}{l}\text { Flowers } \\
\text { per head }\end{array}$ & $\begin{array}{l}0.138 \\
P=0.043\end{array}$ & $\begin{array}{l}0.216 \\
P=0.023\end{array}$ & $\begin{array}{l}0.180 \\
P=0.021\end{array}$ & $\begin{array}{l}0.280 \\
P<0.001\end{array}$ & $\begin{array}{l}0.216 \\
P=0.003\end{array}$ & $\begin{array}{l}0 \\
P=0.5 \\
0.248 \\
P=0.004\end{array}$ & $\begin{array}{l}0.010 \\
P=0.862\end{array}$ & $\begin{array}{l}-0.014 \\
P=0.806\end{array}$ \\
\hline $\begin{array}{l}\text { Flowering } \\
\text { date }\end{array}$ & $\begin{array}{l}0.023 \\
P=0.729\end{array}$ & $\begin{array}{l}-0.151 \\
P=0.109\end{array}$ & $\begin{array}{l}-0.127 \\
P=0.098\end{array}$ & $\begin{array}{l}-0.099 \\
P=0.249\end{array}$ & $\begin{array}{l}-0.177 \\
P=0.013\end{array}$ & $\begin{array}{l}-0.209 \\
P=0.008\end{array}$ & $\begin{array}{l}0.097 \\
P=0.093 \\
0.358 \\
P<0.001\end{array}$ & $\begin{array}{l}-0.037 \\
P=0.572\end{array}$ \\
\hline Flower size & $\begin{array}{l}0.059 \\
P=0.357\end{array}$ & $\begin{array}{l}0.146 \\
P=0.100\end{array}$ & $\begin{array}{l}0.161 \\
P=0.026\end{array}$ & $\begin{array}{l}0.293 \\
P<0.001\end{array}$ & $\begin{array}{l}0.210 \\
P=0.002\end{array}$ & $\begin{array}{l}0.230 \\
P=0.003\end{array}$ & $\begin{array}{l}-0.204 \\
P=0.008\end{array}$ & $\begin{array}{l}0.108 \\
P=0.085 \\
0.185 \\
P=0.019\end{array}$ \\
\hline
\end{tabular}

Åhus population (Table 2), whereas the mean heritability (over characters) turned out to be consistent between the two studies. Hence, caution should be used when interpreting of the (co)variance estimates for particular traits or trait associations.

There was no evidence for genetic erosion in the small Hällestad population relative to the large Åhus population. In fact, slightly higher heritabilities were found in the Hällestad population compared to the Åhus population. Only a few additive covariances reached significance, none of which involved the two fitness components, suggesting that a substantial portion of the variation is unconstrained by linkage or pleiotropy. Given the small size of the Hällestad population $(\approx 25$ plants) and assuming that experimental populations in the greenhouse can be used to infer the genetic architecture of natural populations, these findings indicate that it takes many generations before genetic drift reduces the additive genetic variance of a population and/or that the current number of plants underestimates the long-term population size. Although the number of plants in the population was small $(\approx 25)$ when sampling occurred in 1993, historical evidence indicates a larger population size in the recent past (Waldmann \& Andersson, 1998). Moreover, most of the traits in this study are complex traits expressed relatively late in the life-cycle, and the input of mutational variance each generation could be substantial for such traits (Houle et al., 1996).

The variance attributed to dominance was significant $(P=0.05)$ for eight characters in the Hällestad population (mean 0.263) and for four characters in the Åhus population (mean 0.149). Similarly, the Hällestad population displayed significant dominance covariance for a 
larger number of trait combinations than the Ahus population (18 vs. three). However, the difference was smaller when adjusted for multiple comparisons. These associations showed the same pattern as the additive covariances, i.e. positive associations among size variables and negative associations involving flowering date. Assuming that the dominance (co)variance is expressed in the field and that the Hällestad population will remain small for several generations, it is possible that some of the non-additive variance will be 'converted' into additive variance (Wang et al., 1998; López-Fanjul et al., 1999), perhaps counteracting the (expected) loss of additive variance due to genetic drift. However, the increase in additive variance in the flush phase of a bottleneck may be too small to override the negative effects of inbreeding depression (López-Fanjul et al., 1999), unless (i) the bottleneck is accompanied with a change in the environment so that harmful alleles becomes beneficial, or (ii) there are heterotic effects in matings between different (bottlenecked) lines (Wang et al., 1998).

In another crossing experiment with the Hällestad population, inbred plants were found to produce smaller leaf rosettes, shorter stems, fewer heads, fewer flowers per head and smaller flowers, than plants derived from outcross pollinations (Waldmann \& Andersson, unpublished). Such inbreeding depression is usually attributed to the unmasking of deleterious recessive genes in homozygous individuals and could therefore imply that there are high levels of dominance variance in the population (Lynch \& Walsh, 1998). Hence, it is not surprising that the present investigation detected significant levels of dominance variance for all characters in the Hällestad population. Recently, there has also been interest in the correlated response to inbreeding between characters (e.g. Husband \& Schemske, 1995). In an inbreeding study, Waldmann and Andersson (unpublished) found correlated responses to inbreeding between some characters: maternal families that showed high inbreeding depression in plant stature also showed high inbreeding depression in flower number per head and flower size. These responses are consistent with the relative high dominance covariance between plant height and flower number per head (0.280) and between plant height and flower size (0.293) in this population (Table 5). However, the large number of significant dominance covariances in the Hällestad population (Table 5) also includes combinations of traits for which no correlated inbreeding response was detected (cf. Waldmann \& Andersson, unpublished).

It is widely assumed that directional or stabilizing selection leads to a reduction in the additive genetic variance (Falconer \& Mackay, 1996; Lynch \& Walsh,
1998). Consequently, the proportion between dominance and additive variance $\left(D_{\alpha}\right)$ should be higher for a fitness component than for a character with a weak influence on fitness. Available evidence from other species is consistent with this prediction (Roff, 1997; Merilä \& Sheldon, 1999), but the results of the present study are inconclusive. Head number, a major determinant of fitness, had a lower heritability than traits related to phenology (flowering date) and morphology (flowering date, leaf size, plant height, flower size), especially in the Åhus population. However, flower number per head had a relatively high heritability in the Åhus population, and the Hällestad population had a relatively high heritability for rosette leaf number, another character that might be regarded as a fitness component. Similarly, the dominance contribution was not consistently higher for fitness components than for the other characters. Although head number had a higher $D_{\alpha}$ value than the other characters in the Åhus population, no evidence was found for dominance variance in flower number per head in this population. As for the Hällestad plants, the $D_{\alpha}$ values for head number and flower number per head were close to the mean for the remaining characters.

In previous studies of $S$. canescens and $S$. columbaria (Waldmann \& Andersson, 1998, 1999; 2000), heritabilities were estimated from the variance within and between open-pollinated families. These analyses relied on three assumptions: (i) that offspring within families were related as full-sibs, (ii) that all the genetic variation was additive and (iii) that the maternal effects were negligible. Any departure from the full-sib assumption would make it necessary to multiply the between-family component by a larger constant to yield $V_{\mathrm{A}}$ (e.g. four in the case of half-sibs; Lynch \& Walsh, 1998), leading to higher heritability estimates. As noted above, the mean of the full-sib heritabilities was close to the mean of the narrow-sense estimates (Table 2), so the full-sib assumption seems reasonable for $S$. canescens and possibly also for $S$. columbaria, a closely related species with similar pollination ecology (personal observation). The presence of non-additive variance would lead to an upward bias of the heritability, especially for full-sib estimates (which includes $1 / 4$ of $V_{\mathrm{D}}$ and $1 / 4$ of $\mathrm{V}_{\mathrm{I}}$; Lynch \& Walsh, 1998). However, based on data on additive and dominance variance in the current study (Tables 3-5), the calculated bias in the 'average' character was found to be small: 0.066 for heritabilities in the Hällestad population and 0.037 for heritabilities in the Åhus population (unpublished data). Finally, no evidence was found for maternal effects in $S$. canescens, a possible reflection of the small number of 'seedling characters' measured in this study (Roach \& Wulff, 1987). 
In conclusion, for quantitative genetic analyses to be useful for conservation purposes, it is necessary to take stochastic factors (genetic drift, sampling bias) into account and to estimate quantitative genetic parameters from large samples obtained over several generations. Results from the present study suggest that genetic variances for individual traits can fluctuate widely between generations, probably as a consequence of sampling bias resulting from the limited number of parents in this experiment. Unfortunately, the estimation of genetic parameters in small populations of threatened species is permeated with practical problems.

\section{Acknowledgements}

I thank Stefan Andersson and the referees for comments on the manuscript. Financial support was provided by the World Wildlife Fund (to S.A. and P.W.), and by Fysiografiska Sällskapet i Lund and Miljöstiftelsen Återvinsten (to P.W.).

\section{References}

ARONSSON, M. (ed.) 1999. Rödlistade kärlväxter i SverigeArtfakta. [Swedish red data book of vascular plants]. ArtDatabanken, SLU, Uppsala, Sweden.

BRYANT, E. H., MCCOMmAS, S. A. AND COMBS, L. M. 1986. The effect of an experimental bottleneck upon the quantitative genetic variation in the housefly. Genetics, 114, 1191-1211.

BÜRGER, R. AND GIMELFARB, A. 1999. Genetic variation maintained in multilocus models of additive quantitative traits under stabilizing selection. Genetics, 152, 807-820.

BÜRGER, R. AND LANDE, R. 1994. On the distribution of the mean and variance of a quantitative trait under mutationselection-drift balance. Genetics, 138, 901-912.

CHEVERUD, J. M., VAUGHN, T. T., PLETSCHER, L. S., KING-ELLISON, K. ET AL. 1999. Epistasis and the evolution of additive genetic variance in populations that pass through a bottleneck. Evolution, 53, 1009-1018.

CRNOKRAK, P. AND ROFF, D. A. 1995. Dominance variance: associations with selection and fitness. Heredity, 75, 530-540.

FALCONER, D. S. AND MACKAY, T. F. C. 1996. Introduction to Quantitative Genetics, 4th edn. Longman, New York.

Frankham, R. 1995. Conservation genetics. Ann. Rev. Genet., 29, 305-327.

GENSTAT 5. 1997. Release 4.1. Lawes Agricultural Trust, Rothamsted Experimental Station, Rothamsted, U.K.

HOHLS, т. 1996. Setting confidence limits to genetic parameters estimated by restricted maximum likelihood analysis of North Carolina design II experiments. Heredity, 77, 476-487.

HOULE, D. 1992. Comparing evolvability of quantitative traits. Genetics, 130, 195-204.
HOUle, D., MORIKAWA, B. AND LYNCH, M. 1996. Comparing mutational variabilities. Genetics, 143, 1467-1483.

HUSBAND, B. C. AND SCHEMSKE, D. W. 1995. Magnitude and timing of inbreeding depression in a diploid population of Epilobium angustifolium (Onagraceae). Heredity, 75, 206-215.

LANDE, R. 1998. Anthropogenic, ecological and genetic factors in extinction and conservation. Res. Pop. Ecol., 40, 259-269.

LÓPEZ-FANJUl, C., FERNÁNDEZ, A. AND TORO, M. A. 1999. The role of epistasis in the increase in the additive genetic variance after population bottlenecks. Genet. Res., 73, 45-59.

LYNCH, M. 1996. A quantitative-genetic perspective on conservation issues. In: Avise, J. C. and Hamrick, J. L. (eds) Conservation Genetics: Case Histories from Nature, pp. 471-501. Chapman \& Hall, New York.

LYNCH, M. AND WALSH, B. 1998. Genetics and Analysis of Quantitative Traits. Sinauer Associates, Sunderland, MA.

MERILÄ, J. AND SHELDON, B. C. 1999. Genetic architecture of fitness and nonfitness traits: empirical patterns and development of ideas. Heredity, 83, 103-109.

MORRELL, C. H. 1998. Likelihood ratio testing of variance components in the linear mixed-effects model using restricted maximum likelihood. Biometrics, 54, 1560-1568.

ROACH, D. A. AND WULFF, R. D. 1987. Maternal effects in plants. Ann. Rev. Ecol. Syst., 18, 209-235.

ROFF, D. A. 1997. Evolutionary Quantitative Genetics. Chapman \& Hall, New York.

SCHEMSKE, D. S., HUSBAND, B. C., RUCKELSHAUS, M. H., GOODWILLIE, C. ET AL. 1994. Evaluating approaches to the conservation of rare and endangered plants. Ecology, 75, 584-606.

SEARle, S. R., CASELlA, G. AND MCCUlloch, C. E. 1992. Variance Components. John Wiley and Sons, New York.

SHAW, R. G. 1987. Maximum-likelihood approaches applied to quantitative genetics of natural populations. Evolution, 41, 812-826.

WALDMANN, P. AND ANDERSSON, S. 1998. Comparison of quantitative genetic variation and allozyme diversity within and between populations of Scabiosa canescens and $S$. columbaria. Heredity, 81, 79-86.

WALDMANN, P. AND ANDERSSON, S. 1999. Multilocus and multitrait differentiation of populations of the locally rare plant Scabiosa canescens and the more common S. columbaria. Hereditas, 130, 341-343.

WALDMANN, P. AND ANDERSSON, S. 2000. Comparison of genetic (co) variance matrices within and between Scabiosa canescens and S. columbaria. J. Evol. Biol., 13, 826-835.

WANG, J., CABAllero, A., KeIGHTLEY, P. D. AND HILL, W. G. 1998. Bottleneck effect on genetic variance: a theoretical investigation of the role of dominance. Genetics, 150, 435-447.

WHITLOCK, M. C. AND FOWLER, K. 1999. The changes in genetic and environmental variance with inbreeding in Drosophila melanogaster. Genetics, 152, 345-353.

ZENG, Z.-B. AND COCKERHAM, C. C. 1991. Variance of neutral genetic variances within and between populations for a quantitative character. Genetics, 129, 535-553. 